Check for updates

Bern, Switzerland

serena.tinari@re-check.ch catherine.riva@re-check.ch Cite this as: $B M J 2021 ; 374: n 1737$ http://dx.doi.org/10.1136/bmj.n1737 Published: 13 July 2021

\title{
VACCINATION
}

\section{Donuts, drugs, booze, and guns: what governments are offering people to take covid-19 vaccines}

\section{As the race to vaccinate the world accelerates, some countries are using novel methods to persuade those who are less forthcoming. Serena Tinari and Catherine Riva report}

Serena Tinari, Catherine Riva

In Ohio, you could get a covid-19 vaccine ... and the chance to win a million dollars. "Vax a Million," a state funded public outreach campaign, consisted of a five weekly lottery drawing for those taking their covid-19 shots. For Ohioans aged 12 to 17, there was a draw for five four-year university scholarships.

Cash, donuts, fishing and hunting licences, entry to museums, zoos, concerts or a sports game: these are just some of the offerings to people if they take a covid-19 jab in the US. " "Get a shot and have a beer," teetotaller President Joe Biden had said, ${ }^{3}$ which New Jersey took literally with its "Shot and a Beer" campaign. ${ }^{4}$ Others go further: Washington state offers "Joints for Jabs" 5 and Michigan, "Pot for Shots." 6 In West Virginia, the "Call to Arms" vaccine initiative will be paid for using federal pandemic relief funds. It promises to the vaccinated cash, trucks, and guns. ${ }^{7}$

And it's not just the US. In Canada, children as young as 12 have been offered ice cream for vaccines. ${ }^{8}$ The Netherlands has one place offering soused herrings. ${ }^{9}$ In Chang Mai, Thailand, you might win a cow. ${ }^{10}$ Hong Kong has gold bars and a Tesla on offer. ${ }^{11}$ In Romania, the Dracula castle has been transformed into a fancy vaccination centre to attract people. ${ }^{12}$ Some have turned instead to disincentives not to vaccinate (box).

As coronavirus variants dominate the news, and some batches of vaccine approaching expiry dates, health officials appear to be doing whatever it takes to get vaccination levels up, particularly in the face of vaccine hesitancy. But Ana Santos Rutschman, a legal scholar at Saint Louis University School of Law, has serious concerns about the trend, particularly where cash is concerned.

Rutschman argues that paying people "is undesirable against the backdrop of a pandemic marked by the intertwined phenomena of health misinformation and mistrust in public health authorities. Even beyond the context of covid-19, paying for vaccination is a dubious public health policy likely to backfire in terms of (re)building public trust in vaccines."13

\section{Trust and mistrust}

Maya J Goldenberg, a philosopher of medicine who has published a book on the complexity of vaccine hesitancy, ${ }^{14}$ says incentives fail to address the underlying problem. "Incentive programmes do not target the trust relationship between the public and the providers," Goldenberg told The BMJ. "They are meant to gently steer the 'fence sitters' in favour of the desired behaviour" (a recent Kaiser Family
Foundation ${ }^{15}$ survey found nearly four in 10 adults in the "wait and see" group plan to wait more than a year before getting vaccinated).

Ross D Silverman, a health policy expert at Indiana University, said that incentives "focus on individual awards, rather than, say, offering a benefit should $85 \%$ of a community choose to get vaccinated." He is concerned that they signify the limited success of common good-based public health messaging and are at risk of drawing public resources away from addressing underlying structural barriers in vaccine outreach programmes. "I'd rather government agencies not use incentives like guns, alcohol, and cannabis for these programmes," he told The BMJ.

Allyson Pollock, who directs Newcastle University's Centre for Excellence in Regulatory Science, agrees. "These programmes are the antithesis of good public health practice and are grounded in commercial interests, not public health," she says. "Vaccination policies should be built on information, trust, and consent and not coercion and bribes. The policies of these incentives are adding public health harms as incentives for vaccine uptake.”

In the US in particular, Pollock worries about the lack of universal health insurance and high costs of care. "What are the safeguards for people who suffer adverse health events as a result of vaccination and have no insurance cover?”

\section{Unintended consequences}

Ana Santos Rutschman says small tokens like donuts or beer "do not strike me as posing the same type of ethical problems as direct payments" and that raffles and lotteries-being unpredictable and with low odds of winning-are in her view preferable to cash prizes.

But others say incentives of any kind could still selectively pressure people of lower socioeconomic status over others. Goldenberg asked: "What do those who don't win the lottery get? They are vaccinated (a benefit), but if they feel mistreated because they were compelled to do it (ie, because the unjust system makes college out of reach for many), then there is legitimate moral harm."

Poorly designed incentives may ultimately backfire. Research conducted by behavioural economist George Loewenstein has shown that people believe a study's riskiness to be greater when payment is higher. ${ }^{16}$ In a recent article in the New York Times, Loewenstein and a colleague write: "Humans don't respond to 
incentives like rats pressing levers for food; they try to interpret what being offered payment means. In this case, the offer risks implying that the vaccine is not a thing of value." ${ }^{17}$

\section{Disincentives}

While rewards dominate, some locales have turned to retribution. In the Philippines, President Rodrigo Duterte has stated: "Get vaccinated or l'll jail you." ${ }^{18}$ And while Serbia is offering the vaccinated $€ 25$ ( $\left.f 21, \$ 29\right)$ (around 1.5 days' earnings for the average worker), ${ }^{19}$ its president announced that unvaccinated public sector employees would no longer be eligible for sick pay if they contracted covid-19. ${ }^{20}$

Various governments and businesses are considering the case for employees-health workers in particular. ${ }^{21}$ In Moscow, two million people in public-facing jobs have been told they must be vaccinated by the city's mayor. Businesses will be monitored to make sure they comply, with at least $60 \%$ of employees needing a first dose by 15 July or firms risking being fined. In May, Saudi Arabia's government said employees in the public, private, and non-profit sectors must be vaccinated before they can return to work. And the city of San Francisco has announced a similar requirement for its 35000 public employees, to take effect once the covid-19 vaccines are approved. ${ }^{22}$

Competing interests: Serena Tinari and Catherine Riva are the co-founders and co-chairs of Re-Check, Investigating and Mapping Health Affairs.

Provenance and peer review: Commissioned; not externally peer reviewed.

1 DeWine M. Don't roll your eyes at Ohio's vaccine lottery. New York Times 2021. https://www.nytimes.com/2021/05/26/opinion/ohio-vaccine-lottery-mike-dewine.html?action=click\&module=Opinion\&pgtype=Homepage

2 National Governors Association. COVID-19 vaccine incentives. 2021. https://www.nga.org/center/publications/covid-19-vaccine-incentives/

3 Miller Z. Free beer, other new incentives for Biden's 'vaccine sprint.' Associated Press News 2021 https://apnews.com/article/coronavirus-pandemic-business-government-and-politics-health8168ae1c68ca955b620082d862c911ad

4 New Jersey COVID-19 Information Hub. What is the New Jersey "Shot and a Beer" program? What breweries are participating? 2021. https://covid19.nj.gov/faqs/nj-information/slowing-thespread/what-is-the-new-jersey-\%E2\%80\%9Cshot-and-a-beer\%E2\%80\%9D-program-whatbreweries-are-participating

5 State W. Liquor and Cannabis Board media release: LCB allows "Joints for Jabs" promotions to support vaccinations. 2021. https://content.govdelivery.com/accounts/WALCB/bulletins/2e303d6

6 The Greenhouse of Walled Lake. The Greenhouse of Walled Lake "Pot for Shots" sponsored by UBaked. Press Release. 2021. https://www.greenhousemi.com/pot-for-shots

7 State of West Virginia. COVID-19 UPDATE: Gov. Justice announces big cash, trucks, and scholarships among top prizes in upcoming vaccination incentive lottery. 2021. https://governor.wv.gov/News/press-releases/2021/Pages/COVID-19-UPDATE-Gov.-Justice-announces-bigcash,-trucks,-and-scholarships-among-top-prizes-in-upcoming-vaccination-lottery.aspx

8 Draaisma M. Over 2500 doses of COVID-19 vaccine issued at pop-up clinic held at Toronto city hall. CBC 2021. https://www.cbc.ca/news/canada/toronto/toronto-covid-19-vaccine-clinic-cityhall-rotunda-1.6038133

9 Henley J. Netherlands offers free herring as Covid jab incentive. Guardian 2021. https://www.theguardian.com/world/2021/jun/17/netherlands-offers-free-pickled-herring-ascovid-jab-incentive

10 Thepgumpanat P. Cattle for raffle gets Thai town in mood for vaccines. Reuters 2021. https://www.reuters.com/world/asia-pacific/thai-town-offers-free-cows-boost-vaccine-campaign2021-05-20/

11 Tam F. Tesla, gold bars added to Hong Kong’s \$15 million vaccine incentive prizes. Bloomberg 2021. https://www.bloomberg.com/news/articles/2021-06-09/tesla-gold-bars-added-to-hongkong-s-15-million-vaccine-prizes

12 Ilie L. Dracula's castle lures visitors with COVID-19 jabs. Reuters 2021. https://www.reuters.com/world/europe/vlad-vaccinator-draculas-castle-lures-visitors-with-covid19-jabs-2021-05-08/

13 Santos Rutschman A. Why the government shouldn't pay people to get vaccinated against COVID-19. Bill of Health, Petrie-Flom Center at Harvard Law School 2020. https://blog.petrieflom.law.harvard.edu/2020/12/01/payment-covid-vaccine-incentive/

14 Goldenberg MJ. Vaccine hesitancy: public trust, expertise, and the war on science. University of Pittsburgh Press, 2021. https://www.bibliovault.org/BV.book.epl?ISBN=9780822946557

15 KFF. COVID-19 vaccine monitor: June 2021. https://www.kff.org/coronavirus-covid-19/poll-finding//kf-covid-19-vaccine-monitor-june-2021/
16 Ariely D, Loewenstein G, Prelec D. Tom Sawyer and the construction of value. J Econ Behav Organ2006;60:1-10. doi: 10.1016/j.jebo.2004.10.003. https://www.sciencedirect.com/science/article/abs/pii/S0167268105001265?casa_token=kkZOVCXC9D8AAAAA:TcJkxrT-ESePbgXORyWD9yr18ZKAPR-7xQ5GjB5eiLiocXIk9WwyZniq2y-r1GgINaRjoqz

17 Loewenstein G, Cryder C. Why paying people to be vaccinated could backfire. New York Times 2020. https://www.nytimes.com/2020/12/14/upshot/covid-vaccine-payment.html

18 Ranada P. Duterte threatens to arrest people who refuse getting vaccinated. Rappler 2021. https://www.rappler.com/nation/duterte-order-arrest-people-who-refuse-to-get-vaccinated

19 Holt E. Serbia begins paying citizens to receive a COVID-19 vaccine. Lancet 2021;397:1793.

20 Serbia in 'world first' as citizens offered $€ 25$ to have COVID vaccine. Euronews 2021. https://www.euronews.com/2021/05/05/serbia-in-world-first-as-citizens-offered-25-to-havecovid-vaccine

21 Stokel-Walker C. Covid-19: The countries that have mandatory vaccination for health workers. BMJ 2021;373.n1645.

22 Doshi P. Covid-19 vaccines: In the rush for regulatory approval, do we need more data?BMJ 2021;373:n1244. 